\title{
A convenient UHPLC-MS/MS method for routine monitoring of plasma and brain levels of nicotine and cotinine as a tool to validate newly developed preclinical smoking model in mouse
}

\author{
Mohammad A. Kaisar ${ }^{1}$, Raja Reddy Kallem², Ravi K. Sajja', Ali Ehsan Sifat ${ }^{1}$ and Luca Cucullo ${ }^{1,3^{*}}$ (]
}

\begin{abstract}
Background: A sensitive, rapid and selective UHPLC-MS/MS method has been developed and validated for the quantification of Nicotine (NT) and Cotinine (CN) using Continine- $d_{3}$ as internal standard (IS) as per FDA guidelines. Sample preparation involved simple protein precipitation of $20 \mu \mathrm{L}$ mouse plasma or brain homogenate using acetonitrile at 1:8 ratio. Mass Spectrometer was operated in positive polarity under the multiple reaction-monitoring mode using electro spray ionization technique and the transitions of $\mathrm{m} / \mathrm{z} 163.2 \rightarrow 132.1,177.2 \rightarrow 98.0$ and $180.2 \rightarrow 101.2$ were used to measure the NT, CN and IS, respectively. The elution of NT, CN and IS are at 1.89, 1.77 and $1.76 \mathrm{~min}$, respectively. This was achieved with a gradient mobile phase consisting of $5 \mathrm{mM}$ ammonium bicarbonate, acetonitrile and methanol $(3: 1, \mathrm{v} / \mathrm{v})$ at a flow rate of $0.3 \mathrm{~mL} / \mathrm{min}$ on a Kinetex EVO C18 column. The method was validated with a lower limit of quantitation $3.0 \mathrm{ng} / \mathrm{mL}$ in mouse plasma and brain for both the analytes.

Results: A linear response function was established for the range of concentrations 3-200 ( $r>0.995)$ for NT and 3-600 ng/mL ( $r>0.995)$ for CN. The intra- and inter-day precision values met the acceptance criteria. NT and CN are stable in the battery of stability studies viz., stock solution, bench-top and auto-sampler.

Conclusion: This method was successfully utilized to validate a newly developed preclinical smoking model in mice.

Keywords: Nicotine, Cotinine, Mouse plasma, Preclinical, animal model, Tobacco smoke, Method validation,

UHPLC-MS/MS
\end{abstract}

\section{Background}

Tobacco smoking (TS) adversely impacts public health by contributing to enormous health-related economic losses and countless deaths each year. Exposure to tobacco constituents through active or passive smoking harms several organs resulting in an increased risk of lung diseases, cardio/cerebrovascular disorders and cancers [1]. TS is

\footnotetext{
*Correspondence: luca.cucullo@ttuhsc.edu

${ }^{1}$ Department of Pharmaceutical Sciences, School of Pharmacy, Texas Tech University Health Sciences Center, 1300 S. Coulter Street, Amarillo, TX 79106, USA

Full list of author information is available at the end of the article
}

considered as the leading cause of preventable disease and death in the United States, accounting for more than 480,000 deaths every year, or 1 of every 5 deaths [2]. In 2015, about 15 of every 100 U.S. adults aged 18 years or older smoked cigarettes. This means an estimated 36.5 million adults in the United States currently smoke cigarettes. More than 16 million Americans live with a smoking-related disease.

Nicotine (NT) is the major bioactive and addictive constituent of TS and is rapidly metabolized into cotinine $(\mathrm{CN})$ and other less abundant metabolites primarily by the liver cytochrome P450s. The plasma level of NT in chronic smokers generally average between 20 
and $60 \mathrm{ng} / \mathrm{mL}$ although depending on a number of variables (including volume, depth of inhalation, and frequency; type of cigarette smoked and relative nicotine yield; number, age, and gender of the sample population being tested as well as the time the samples were collected during testing) plasma nicotine concentration can raise up to $100 \mathrm{ng} / \mathrm{mL}[3,4]$. By contrast, the plasma concentration of $\mathrm{CN}$ is significantly higher (ranging between 250 and $350 \mathrm{ng} / \mathrm{mL}$ ) and remains fairly stable. NT has a very short half-life of $\sim 2 \mathrm{~h}$ but its primary metabolite $\mathrm{CN}$ has significantly higher plasma half-life of approximately $16 \mathrm{~h}$ [3]. Because of the longer halflife $\mathrm{CN}$ is considered a well established biomarker for TS exposure [3, 5-7]. Investigational studies to comprehend the mechanisms underlying the CNS effects of $\mathrm{NT}$ in biological tissues do require sensitive and specific measurement of both the parent compound and its metabolite $\mathrm{CN}$ originated from TS.

Preclinical studies using animal models with unique protocols are critically important to identify biomarkers for TS related disorders, dissect their pathophysiology and to assess the preventive/therapeutic efficacy of drugs prior to any clinical trial. If the target organ of interest is brain, working on clinical subjects is nearly impossible since it is an invasive terminal procedure. Several animal models and different protocols have been used for preclinical research. This includes, transdermal implantation of osmotic mini pump [6, 8], IV injection of nicotine/tobacco extract solution $[9,10]$, direct inhalation of TS in animal restraint device [11]. Most of these exposure conditions fail to simulate realistic smoking behavior. Concerning the appropriate rodent model to use to study the impact of smoking in humans the animal of choice is primarily dependent upon the objective of the studies. In fact, while mice seem better-suited models to simulate the nicotine metabolism in humans based on structural and functional similarities of the respective metabolizing enzymes (in humans nicotine is primarily metabolize by the cytochrome P450 enzyme CYP2A6 which shares close functional efficiency [12,13] and $84 \%$ amino acid sequence similarity $[14,15]$ with that of the mice; the CYP2A5); rats (where nicotine metabolism is instead largely under the control of P450 CYP2B family of enzymes [16]) seems to provide a more translationally relevant pharmacokinetic model when considering the effective rate of nicotine elimination (the nicotine T1/2 in humans is approximately $2 \mathrm{~h}$ while in rats is about $1 \mathrm{~h}$ and only $15 \mathrm{~min}$ in mice [17-19]). Despite these differences, both rats and mice serve as purposeful and translatable models for preclinical smoking research. Herein, we report a newly developed preclinical smoking model using C57BL/6 mice. Our exposure condition mimics the behavior, intensity and smoking pattern of a chronic heavy smokers and can be used either for acute or long term in vivo studies.

Abundant literature available on simultaneous estimation of NT and $\mathrm{CN}$ in human plasma, serum, urine and saliva using gas chromatography-mass spectrometry (GC-MS) and liquid chromatography-tandem mass spectrometry (LC-MS/MS) technics. Recent publication by Abdallah et al. [20] and Tretzel et al. [21] have comprehensively discussed on the various bioanalytical methods published for the simultaneous quantification of NT and $\mathrm{CN}$ in human serum, plasma or urine samples. Whereas Vieira-Brock et al. [22] have extensively discussed about all currently available methods for the estimation of NT and $\mathrm{CN}$ in rat plasma or brain homogenate. All these groups opined that most of these reported methods (GC, CE and LC-MS/MS) had the limitation of sensitivity, tedious sample preparation procedure, very long run times and/or higher sample volumes. Though Alsharari et al. [23] mentioned some details of their method in mouse plasma, the main limitations of the method were $200 \mu \mathrm{L}$ sample volume, longer procedure for sample preparation and poor sensitivity. Therefore, we required to develop and validate a sensitive, rapid, cost effective and simple UHPLC-MS/MS method for the simultaneous estimation of NT and $\mathrm{CN}$ in mice plasma and brain samples. This newly developed method was successfully utilized to validate our preclinical smoking model in mice demonstrating the extent of exposure to TS.

\section{Methods}

\section{Chemicals and reagents}

(-)-Nicotine (Cat \# 36733); (-)-Cotinine, $1 \mathrm{mg} / \mathrm{mL}$ solution in methanol (Cat \# C0430); deuterated internal standard (IS) ( \pm )-Cotinine- $d_{3}$ (see Fig. $1 \mathrm{a}$ ), $1 \mathrm{mg} / \mathrm{mL}$ solution in methanol (Cat \# C-035) and LC/MS grade eluent additive ammonium bicarbonate (Cat \# 40867) were purchased from Sigma-Aldrich, USA. LC/MS grade solvents water (Cat \# W6-4), acetonitrile (Cat \# A955-4) and methanol (Cat \# A456-4) were obtained from Fisher Scientific, USA. Tobacco reference product, 3R4F equivalent to regular cigarettes were purchased from University of Kentucky.

\section{UHPLC-MS/MS instrumentation}

The UHPLC-MS/MS system equipped with AB SCIEX QTRAP $^{\circledR} 5500$ mass spectrometer (Foster City, CA, USA) attached to a Nexera UHPLC system from Shimadzu Corporation (Columbia, MD) was used. The liquid chromatographic unit consisted of a Sil-30AC auto-sampler, LC-30AD binary pumps, a CBM-20A controller, a DGA-20A5 degasser, and a CTO-30A column oven. Data acquisition and quantitation were performed by Analyst software. 


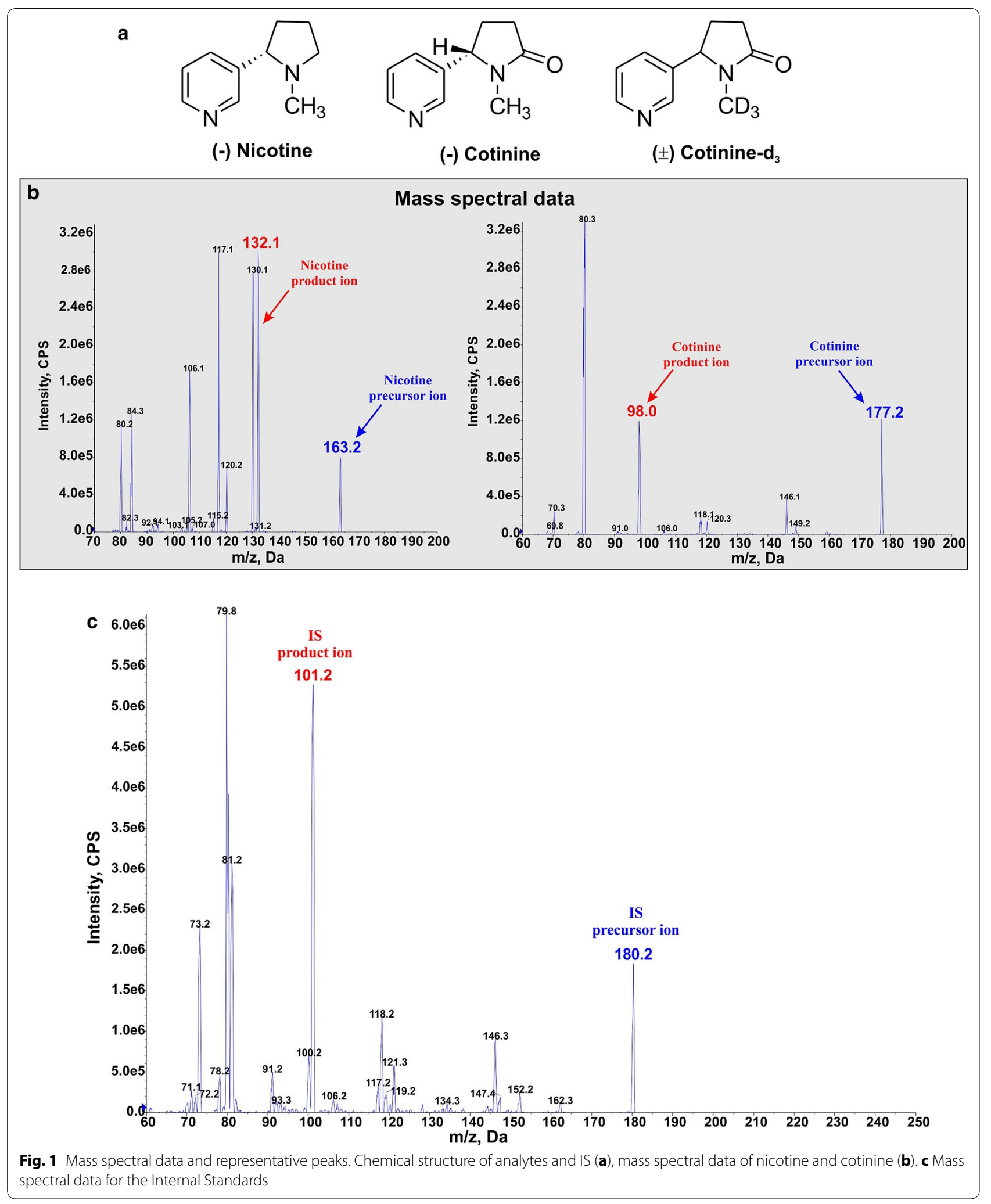




\section{Chromatographic conditions}

Kinetex EVO C18 column $(100 \times 2.1$ mm I.D., $1.7 \mu \mathrm{m}$ particle size, $100 \AA$ pore size) proceeded by SecurityGuard ${ }^{\mathrm{TM}}$ ULTRA guard column (Phenomenex; Torrance, CA, USA) was used to perform the chromatographic separation while column oven was set at $40{ }^{\circ} \mathrm{C}$ temperature. The injection volume was $4 \mu \mathrm{L}$. For the elution of the analytes, gradient flow of a mixture of $5 \mathrm{mM}$ ammonium bicarbonate buffer ( $\mathrm{pH}$ not adjusted) (A) and Acetonitrile: Methanol $(3: 1, \mathrm{v} / \mathrm{v})(\mathrm{B})$ has been used at a flow rate of $0.3 \mathrm{~mL} / \mathrm{min}$. The gradient program started with $10 \%$ $\mathrm{B}$, kept unaltered for 0.40 min which was then raised to 90\% B over $0.8 \mathrm{~min}$. From 0.8 to $2.2 \mathrm{~min}$ the mobile phase composition remained constant followed by switching back to the initial condition in next $0.2 \mathrm{~min}$. The column was re-equilibrated at $10 \% \mathrm{~B}$ for another $0.6 \mathrm{~min}$. Total run time of the method is $3.0 \mathrm{~min}$ with retention time (RT) for both analytes and IS were 1.89 (nicotine), 1.77 (cotinine) and 1.76 (cotinine- $d_{3}$ ) minute, respectively.

\section{Mass spectrometric conditions}

A triple quadrupole mass spectrometer (5500 QTRAP; Foster City, CA, USA) was used for the quantitation of NT, CN and IS. The ionization source was through electro-spray ionization (TurbolonSpray ${ }^{\circledR}$ ), and the analytes were detected using multiple reactions monitoring (MRM) operated in the positive mode by monitoring their transition pairs of $m / z 163.2$ precursor ion to the $m / z 132.1$ for NT, $m / z 177.2$ precursor ion to the $m / z$ 98.0 for $\mathrm{CN}$, and $\mathrm{m} / \mathrm{z} 180.2$ precursor ion to the $\mathrm{m} / \mathrm{z}$ 101.2 product ion for the I.S (see Fig. 1b). The corresponding mass spectral data for the Internal Standards are also shown in Fig. 1c.

Quadrupoles Q1 and Q3 were set on unit resolution with the help of Analyst software ${ }^{\mathrm{TM}}$ (version 1.6.2). The source/gas and compound parameters were optimized to obtain the highest $[\mathrm{M}-\mathrm{H}]+$ ion abundance by infusing the standard solutions of the analyte of interest via a syringe pump into the mass spectrometer. The optimized source/gas parameters were as follows: curtain gas, 35 psi; collision gas, high; ion spray voltage, $5500 \mathrm{~V}$; temperature, $550{ }^{\circ} \mathrm{C}$; ion source gas 1 (nebulizer gas), $50 \mathrm{psi}$; and ion source gas 2 (turbo gas), 50 psi. The compound parameters were optimized for each of the analytes and are represented in Table 1 . The product ion of NT $(\mathrm{m} / z$ 132.1), $\mathrm{CN}(m / z 98.0)$ and IS $(m / z 101.2)$ selected in our study for monitoring are similar to previously reported ions [24].

\section{Preparation of stock solutions, calibration standards and quality control samples}

Stock solution of nicotine: cotinine (1:1, $1 \mathrm{mg} / \mathrm{mL}$ each), nicotine: cotinine $(1: 3,1: 3 \mathrm{mg} / \mathrm{mL})$ and IS $(1 \mu \mathrm{g} / \mathrm{mL})$ were prepared in methanol and stored in $-20{ }^{\circ} \mathrm{C}$. For plasma, nicotine stock solution was diluted to 30,50 , 100, 200, 300, 400, 500, 1000, $2000 \mathrm{ng} / \mathrm{mL}$ (calibration standard) and 30, 90, 750 and $1500 \mathrm{ng} / \mathrm{mL}$ (quality control, $Q C$ samples) in methanol while cotinine stock solution was diluted to $30,150,300,600,900,1200,1500$, $3000,6000 \mathrm{ng} / \mathrm{mL}$ (calibration standard) and 30, 90, 2250 and $4500 \mathrm{ng} / \mathrm{mL}$ (QC samples) in methanol and stored at $-20{ }^{\circ} \mathrm{C}$. For brain, both the nicotine and cotinine stock solution were diluted to $30,50,100,200,300$, $500,750,1000 \mathrm{ng} / \mathrm{mL}$ (calibration standard) and 30, 90, 400, $800 \mathrm{ng} / \mathrm{mL}$ (QC samples) in methanol. Nicotine: cotinine (1:1) stock solution was used for brain matrix, $30,90 \mathrm{ng} / \mathrm{mL}$ stock for plasma matrix and the remaining dilutions for plasma matrix were made from 1:3 nicotine: cotinine stock. $5 \mu \mathrm{L}$ (both calibration standard and QC samples) of stock solution was spiked into $45 \mu \mathrm{L}$ of matrix (either plasma or brain matrix) and vortexed for $30 \mathrm{~s}$. Ten fold dilution of the stock solution by spiking in matrix produced a concentration series of $3,5,10,20$, $30,40,50,100,200 \mathrm{ng} / \mathrm{mL}$ (calibration standard) and 3, 9, 75, $150 \mathrm{ng} / \mathrm{mL}$ (QC samples) of nicotine; 3, 15, 30, 30, 90.120, 150, 300, $600 \mathrm{ng} / \mathrm{mL}$ (calibration standard) and 3, 9, 225, $450 \mathrm{ng} / \mathrm{mL}$ (QC samples) of cotinine in plasma; 3, 5, 10, 20, 30, 50, 75, $100 \mathrm{ng} / \mathrm{mL}$ (calibration standard) and 3, 9, 40 and $80 \mathrm{ng} / \mathrm{mL}$ of both nicotine and cotinine in brain matrix. A linear calibration curve was constructed by plotting ratio of peak area of analyte and IS versus drug concentration. Blank plasma and brain homogenate were collected from control C57BL/6 mice.

Table 1 Compound parameters for analytes and internal standard with MRM in positive electrospray mode

\begin{tabular}{lllllr}
\hline & Q1 mass (Da) & Q3 mass (Da) & DP & CE & CXP \\
\hline Analytes & & & & & \\
$\quad \begin{array}{l}\text { Nicotine } \\
\text { Cotinine }\end{array}$ & 163.2 & 132.1 & 100 & 27 & 10 \\
$\begin{array}{l}\text { Internal standard } \\
\text { Cotinine-D3 }\end{array}$ & 177.2 & 98 & 100 & 34 & 10 \\
\hline
\end{tabular}

$D P$ declustering potential, $C E$ collision energy, $C X P$ collision exit potential, EP entrance potential 


\section{Sample preparation}

50 -fold dilution of IS stock in acetonitrile provided a concentration of $20 \mathrm{ng} / \mathrm{mL} .160 \mu \mathrm{L}$ of IS solution was added to $20 \mu \mathrm{L}$ (1:8) of calibration standard, QC sample or test samples (plasma/brain samples collected from mice exposed to smoke) vortexed for $1 \mathrm{~min}$ at high speed and centrifuged at $14,000 \mathrm{rpm}$ for $25 \mathrm{~min}$ at $4{ }^{\circ} \mathrm{C}$. The remaining $30 \mu \mathrm{L}$ of calibration standard/QC samples were stored at $-80{ }^{\circ} \mathrm{C}$ for future use. The supernatant was transferred carefully into an autosampler inserts for LC-MS/MS analysis. A $4 \mu \mathrm{L}$ sample was injected onto an analytical column.

\section{Method validation}

Intra and inter-run accuracy and precision of quality control samples at lower limit of quantification (LLOQ), low (LQC), middle (MQC) and high (HQC) quality control concentrations $(3,9,75,150 \mathrm{ng} / \mathrm{mL}$ of nicotine and $3,9,225,450 \mathrm{ng} / \mathrm{mL}$ cotinine in plasma; $3,9,40,80 \mathrm{ng} /$ $\mathrm{mL}$ of both nicotine and cotinine in brain) were analyzed against the calibration curve. The accuracy of five repeats of each concentration was estimated using the following equation:

$$
\text { Accuracy }=\frac{\text { Measured concentration }}{\text { Nominal concentration }} \times 100 \%
$$

Precision was measured as percentage relative standard deviation (R.S.D) of accuracy by the following equation:

$$
\text { Precision }=\frac{\text { Standard deviation of accuracy }}{\text { Mean of accuracy }} \times 100 \%
$$

The acceptable limits of accuracy were set to $80-120 \%$ for LLOQ and $85-115 \%$ for LQC, MQC and HQC. Similarly, Precision $\leq 20$ for LLOQ and $\leq 15$ for low, middle and high concentration were considered acceptable.

\section{Selectivity}

Selectivity of the method was assessed by analyzing six different lots of mouse blank plasma and brain samples. The background noises or interferences responses at the retention time of the $\mathrm{NT}$ and $\mathrm{CN}$ should be less than $20 \%$ of the mean response of the lowest standard curve point or LLOQ. The background noises or interferences responses at the retention time of the I.S. shall be acceptable if it is less than $5 \%$ of the mean response of the working I.S. Sensitivity was established from the background noise or response from six lots of blank plasma spiked with LLOQ concentration of analytes. The acceptable limits/error of accuracy and precision between the six replicates is $\pm 20 \%$.

\section{Recovery}

The recovery of nicotine and cotinine from matrix components (both plasma and brain) was estimated by the following equation:

$$
\text { Recovery }=\frac{{\text { Peak } \text { area }_{\text {test }}}_{\text {Peak } \text { area }_{\text {reference }}}}{\text { Pen }} \times 100 \%
$$

Test refers to addition of known quantity of analyte spiked to the matrix before processing whereas reference solutions were prepared by spiking the same amount of analytes after processing the matrix blank. Five repeats of 3 concentrations (same as LQC, MQC and HQC) have been selected for recovery estimation. The recovery of IS was tested at the identical concentration used in the assay.

\section{Matrix effect}

Since sample preparation involved simple protein crash using acetonitrile, matrix effect was investigated to ensure that precision, selectivity and sensitivity are not compromised by the matrix. Matrix effect was quantitatively evaluated at 3 concentrations (same as LQC, $\mathrm{MQC}$ and $\mathrm{HQC}$ ) with five replicates each. Compared the post extraction spiked samples (test) with neat samples (reference) prepared in similar way without plasma or brain homogenate matrix. The acceptable limits of accuracy were set to $80-120 \%$ of nominal concentrations. Similarly, a precision $\leq 20 \%$ is considered acceptable.

Matrix effect of nicotine and cotinine from matrix components (both plasma and brain) was estimated by the following equation:

$$
\text { Accuracy }=\frac{{\text { Peak } \text { area }_{\text {test }}}_{\text {Peak } \text { area }_{\text {reference }}}}{\text { Pen }}
$$

\section{Stability}

Stock solution stability is evaluated at 3 QC levels (LQC, MQC and HQC: $\mathrm{n}=5$ ) for 10 days at refrigerator temperature $\left(4{ }^{\circ} \mathrm{C}\right)$. Stability of the stored samples will be compared against freshly prepared QC samples. Autosampler and bench-top stability tests were performed at 3 QC levels (LQC, MQC and HQC: $\mathrm{n}=5$ ). For autosampler stability, samples were prepared and kept in autosampler $\left(4^{\circ} \mathrm{C}\right)$ for $12 \mathrm{~h}$, whereas another set of samples were left at ambient room temperature for $8 \mathrm{~h}$ prior to sample preparation. The concentrations were calculated against a calibration curve constructed from freshly prepared samples. Stability samples not exceeding the limit of accuracy (i.e., $\pm 15 \%$ ) and precision (i.e., R.S.D 15\%) are considered to be acceptable. 


\section{Application of the method Preclinical smoking model}

The animal studies were carried out in accordance with federal and state guidelines and the animal protocol for this work was approved by the Institutional Animal Care and Use Committee, TTUHSC, Lubbock, Texas. Total sixteen (two groups of eight) animals (C57BL/6J mice, Jackson Laboratories; male population; 8-10 weeks old; body weight: $20-25 \mathrm{~g}$ ) were exposed (via direct inhalation) to side stream smoke from 3R4F research cigarettes (9.4 $\mathrm{mg}$ tar and $0.726 \mathrm{mg}$ nicotine/cigarette-equivalent to full flavor brands; University of Kentucky) 6 times a day, 2 cigarettes/hour/8 animals every day for 7 and 14 days to simulate chronic human smoking behavior and achieve realistic plasma nicotine level of a chronic smoker (see Fig. 2). Tobacco smoke (TS) was generated and forced directly into two airtight smoking chambers (Dimension-24L $\times 12 \mathrm{~W} \times 12 \mathrm{H}$ ) housing the mice $(4$ mice/cage) by CSM-SCSM cigarette smoking machine ( $\mathrm{CH}$ Technologies, Westwood, NJ). TS was generated according to the modified Federal Trade Commission (FTC) standard protocol (1 puff/min, $35 \mathrm{~mL}$ puff depth volume, $4 \mathrm{~s}$ puff duration and 8 puffs in one session). The smoking inlet is dually connected to a feeding tube (0.188 inch ID; length-smoking machine to cage$30 \mathrm{~cm}$, Oxygen cylinder to cage- $150 \mathrm{~cm}$ ) and a ventilator systems supplying $\mathrm{O}_{2}(2 \mathrm{~L} / \mathrm{min})$ at atmospheric levels (1 bar). During the interval between puffs, animals will receive uninterrupted supply of normal oxygenated air. Animals were transferred immediately from the smoking chamber to their regular housings with food and water supply once the smoking session is completed. Once the smoking cycle in last day was complete, $100 \mu \mathrm{L}$ blood sample was collected immediately within $30 \mathrm{~min}$ by cardiac puncture, centrifuged at $1300 \mathrm{~g}$ for $10 \mathrm{~min}$ to obtain the plasma which was stored at $-80^{\circ} \mathrm{C}$. Following decapitation, brain was isolated and preserved at $-80^{\circ} \mathrm{C}$, homogenized in water (1:10 ratio) immediately before use.

Data were expressed as mean \pm SEM and analyzed by one-way ANOVA using GraphPad Prism 6 Software Inc. (La Jolla, CA, USA). Post hoc multiple comparison tests were performed with Tukey's or Dunnett's test. $p$ values $<0.05$ were considered statistically significant.
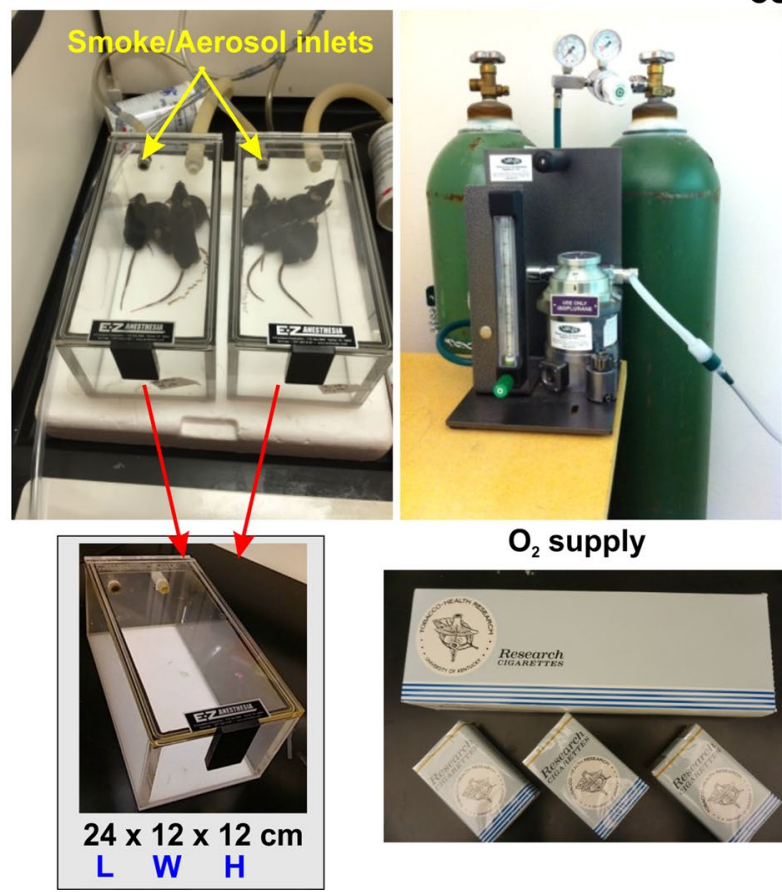

CSM-SCSM computer-controlled smoking machine
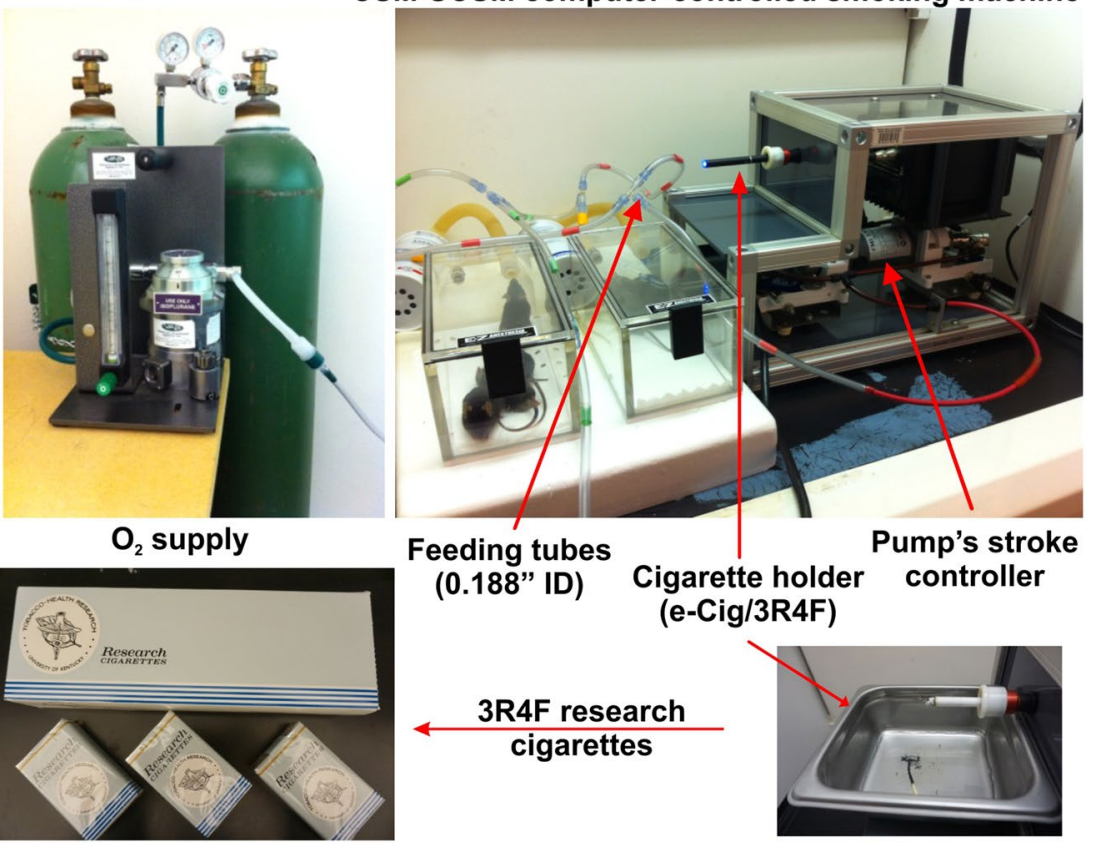

Fig. 2 Preclinical smoking model in mouse. $8(4+4)$ C57BL/6J mice are exposed (via direct inhalation) to side stream smoke generated from 3R4F research cigarettes (also compatible to automatic e-cigarettes). Tobacco smoke (TS) was generated and forced directly into two airtight smoking chambers (Dimension-24L $\times 12 \mathrm{~W} \times 12 \mathrm{H}$ ) housing the mice (4 mice/cage) by single channel cigarette smoking machine. The smoking inlet is dually connected to a feeding tube $(0.188 \mathrm{in}$. ID; length-smoking machine to cage- $30 \mathrm{~cm}$, Oxygen cylinder to cage-150 cm) and a ventilator systems supplying $\mathrm{O}_{2}(2 \mathrm{~L} / \mathrm{min}$ ) at atmospheric levels (1 bar). During the interval between puffs, animals receive uninterrupted supply of normal oxygenated air 


\section{Results}

\section{Calibration curve}

The calibration curve was consistently reproducible over the standard concentration range in both plasma and brain matrix (see Fig. 3). Calibration curve acquired by plotting peak ratio of analyte to IS versus nominal concentration using $1 / \mathrm{X}^{2}$ weighing factor gave regression $>0.99$ in every occasion. The mean accuracy of the back calculated concentrations was found to be $99.98 \%$ with
R.S.D $6.42 \%$ for nicotine and $100 \%$ with R.S.D $4.53 \%$ for cotinine in plasma and $99.99 \%$ with R.S.D $7.01 \%$ for nicotine and $99.99 \%$ with R.S.D $5.87 \%$ for cotinine in brain.

\section{Intra and inter-day accuracy and precision}

Intra and inter-day accuracy and precision were measured by analyzing five replicates of QC samples at four different concentrations as shown in Table 2. For plasma the accuracy ranged from 107.06 to $84.34 \%$ with

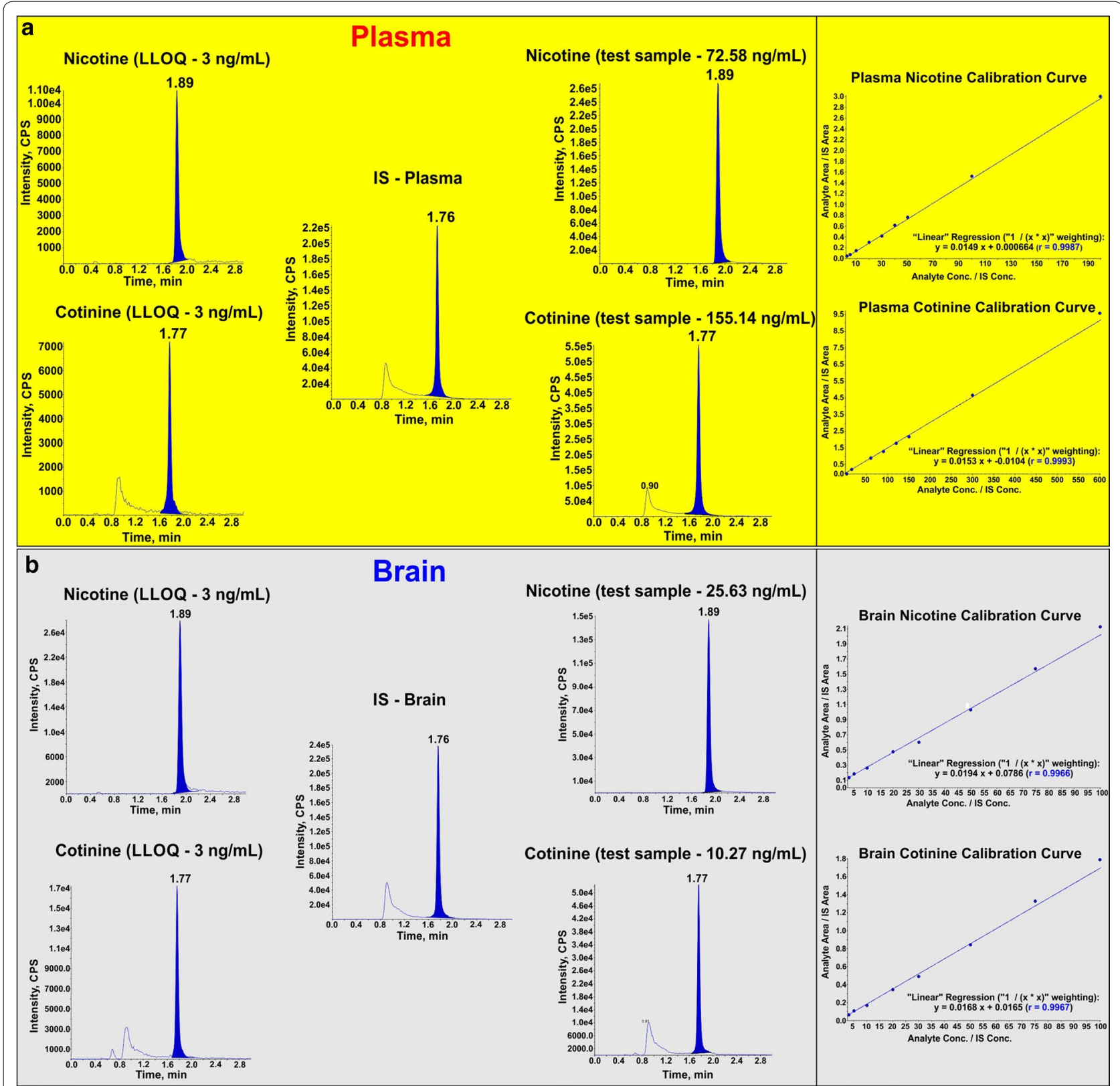

Fig. 3 Representative peaks and calibration curves. Representative peaks of analytes (QC sample) at LLOQ ( $3 \mathrm{ng} / \mathrm{mL})$, IS ( $20 \mathrm{ng} / \mathrm{mL})$ and test samples in plasma (a) and brain (b) matrix. Note also the calibration curves for nicotine-plasma (3-200 ng/mL), cotinine-plasma (3-600 ng/mL), nicotine-brain (3-100 $\mathrm{ng} / \mathrm{mL}$ ) and cotinine (3-100 $\mathrm{ng} / \mathrm{mL})$ with $r>0.99$ 
Table 2 Intra and inter-run accuracy and precision of the $\operatorname{method}(\mathrm{n}=5)$

\begin{tabular}{|c|c|c|c|c|c|}
\hline \multirow{2}{*}{\multicolumn{2}{|c|}{$\begin{array}{l}\text { Concentration } \\
\text { (ng/mL) }\end{array}$}} & \multicolumn{2}{|l|}{ Intra-run } & \multicolumn{2}{|l|}{ Inter-run } \\
\hline & & \multirow[t]{2}{*}{ Accuracy } & \multirow[t]{2}{*}{ R.S.D. (\%) } & \multirow[t]{2}{*}{ Accuracy } & \multirow[t]{2}{*}{ R.S.D. (\%) } \\
\hline \multicolumn{2}{|l|}{ Plasma } & & & & \\
\hline \multicolumn{6}{|l|}{ Nicotine } \\
\hline LLOQ & 3 & 101.49 & 7.50 & 107.06 & 9.53 \\
\hline LQC & 9 & 93.36 & 5.02 & 98.92 & 9.33 \\
\hline MQC & 75 & 89.67 & 3.55 & 89.35 & 4.64 \\
\hline $\mathrm{HQC}$ & 150 & 92.48 & 5.90 & 98.61 & 11.30 \\
\hline \multicolumn{6}{|c|}{ Cotinine } \\
\hline LLOQ & 3 & 84.34 & 3.7 & 94.29 & 10.99 \\
\hline LQC & 9 & 105.98 & 6.93 & 100.25 & 14.40 \\
\hline $\mathrm{MQC}$ & 225 & 90.55 & 1.24 & 89.96 & 6.97 \\
\hline HQC & 450 & 97.89 & 9.5 & 98.31 & 8.13 \\
\hline \multicolumn{6}{|l|}{ Brain } \\
\hline \multicolumn{6}{|l|}{ Nicotine } \\
\hline LLOQ & 3 & 104.26 & 4.36 & 102.59 & 14.48 \\
\hline LQC & 9 & 111.01 & 4.93 & 107.28 & 5.65 \\
\hline $\mathrm{MQC}$ & 40 & 114.45 & 7.36 & 109.44 & 9.10 \\
\hline $\mathrm{HQC}$ & 80 & 113.46 & 6.91 & 110.70 & 7.51 \\
\hline \multicolumn{6}{|c|}{ Cotinine } \\
\hline LLOQ & 3 & 96.66 & 8.59 & 98.55 & 8.01 \\
\hline LQC & 9 & 107.36 & 6.56 & 106.23 & 5.46 \\
\hline $\mathrm{MQC}$ & 40 & 106.64 & 9.68 & 109.61 & 8.20 \\
\hline $\mathrm{HQC}$ & 80 & 112.52 & 1.26 & 113.21 & 1.49 \\
\hline
\end{tabular}

R.S.D $\leq 14.40 \%$ while for brain from 96.66 to $114.4 \%$ with R.S.D $\leq 14.48 \%$.

\section{Recovery and matrix effects}

The recovery of both analytes and IS were estimated from the ratio of peak area for analyte spiked prior to matrix processing to that of analyte spiked following matrix processing. Recovery was measured in three different QC concentrations (LQC, MQC and HQC) from five replicates as mentioned in Table 3. Recovery of nicotine ranged from $95.05 \pm 4.37 \%$ to $103.1 \pm 2.69 \%$ in plasma and $94.96 \pm 3.51$ to $107.57 \pm 6.46 \%$ in brain matrix whereas recovery of cotinine ranged from $89.22 \pm 4.52$ to $103.42 \pm 4.13 \%$ in plasma and $90.37 \pm 3.15 \%$ to $105.60 \pm 3.71 \%$ in brain. Table 4 demonstrates the matrix effects of both plasma and brain. All concentrations met the acceptable limit except few of them marginally showed matrix effects.

\section{Stability}

Figure 4 depicting no significant change in concentrations/absolute peak area of analytes after delay in ambient temperature or in autosampler for 10 and $12 \mathrm{~h}$ respectively.
Table 3 (\%) Recovery (Mean \pm SD) of analytes and IS $(\mathbf{n}=5)$

\begin{tabular}{|c|c|c|c|}
\hline \multicolumn{2}{|c|}{ Concentration (ng/mL) } & \multicolumn{2}{|l|}{ Recovery (\%) } \\
\hline & & Analyte & IS \\
\hline \multicolumn{4}{|l|}{ Plasma } \\
\hline \multicolumn{4}{|l|}{ Nicotine } \\
\hline LQC & 9 & $95.05 \pm 4.37$ & $98.20 \pm 1.86$ \\
\hline MQC & 75 & $103.10 \pm 2.69$ & $100.10 \pm 2.36$ \\
\hline HQC & 150 & $95.00 \pm 8.69$ & $100.53 \pm 1.30$ \\
\hline \multicolumn{4}{|l|}{ Cotinine } \\
\hline LQC & 9 & $89.22 \pm 4.52$ & $98.20 \pm 1.86$ \\
\hline MQC & 225 & $103.42 \pm 4.13$ & $100.10 \pm 2.36$ \\
\hline HQC & 450 & $93.43 \pm 2.49$ & $100.53 \pm 1.30$ \\
\hline \multicolumn{4}{|l|}{ Brain } \\
\hline \multicolumn{4}{|l|}{ Nicotine } \\
\hline LQC & 9 & $101.58 \pm 1.00$ & $95.79 \pm 2.42$ \\
\hline MQC & 40 & $94.96 \pm 3.51$ & $95.14 \pm 1.03$ \\
\hline $\mathrm{HQC}$ & 80 & $107.57 \pm 6.46$ & $95.57 \pm 1.73$ \\
\hline \multicolumn{4}{|l|}{ Cotinine } \\
\hline LQC & 9 & $99.01 \pm 5.34$ & $95.79 \pm 2.42$ \\
\hline MQC & 40 & $90.37 \pm 3.15$ & $95.14 \pm 1.03$ \\
\hline HQC & 80 & $105.60 \pm 3.71$ & $95.57 \pm 1.73$ \\
\hline
\end{tabular}

Table 4 Matrix effects (mean \pm SD) of plasma and brain on analytes $(\mathbf{n}=5)$

\begin{tabular}{lrl}
\hline Concentration $(\mathbf{n g} / \mathbf{m L})$ & & Matrix factor $(\%)$ \\
\hline Plasma & & \\
Nicotine & & \\
LQC & 75 & $75.32 \pm 2.46 \pm 18.97$ \\
MQC & 150 & $77.37 \pm 10.84$ \\
HQC & & \\
Cotinine & 9 & $90.00 \pm 0.30$ \\
LQC & 225 & $78.47 \pm 4.13$ \\
MQC & 450 & $87.08 \pm 11.61$ \\
HQC & & \\
Brain & & \\
Nicotine & 9 & $92.61 \pm 5.12$ \\
LQC & 40 & $91.37 \pm 9.13$ \\
MQC & 80 & $90.54 \pm 7.29$ \\
HQC & & $86.64 \pm 2.38$ \\
Cotinine & 9 & $89.65 \pm 8.49$ \\
LQC & 40 & $91.92 \pm 5.16$ \\
MQC & 80 & \\
HQC & &
\end{tabular}

\section{Validating preclinical smoking model}

Figure 5 shows the plasma and brain levels of nicotine and cotinine in mouse ( $\mathrm{n}=8$ in each case) following one and 2 weeks of chronic exposure. After 1 week exposure, 

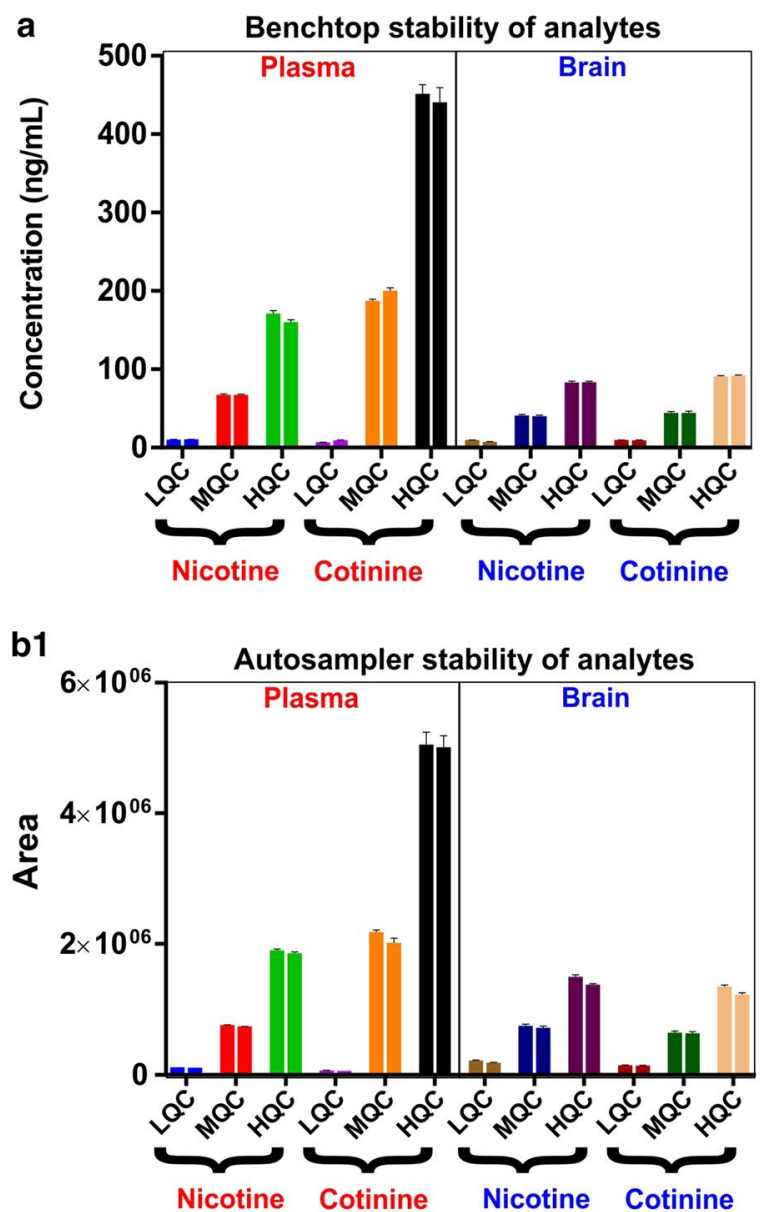

Nicotine-Plasma LQC

Nicotine-Plasma-MQC

Nicotine-Plasma-HQC

Cotinine-Plasma-LQC

Cotinine-Plasma-MQC

Cotinine-Plasma-HQC

b1

Nicotine

Nicotine

Cotinine

b2 Autosampler stability

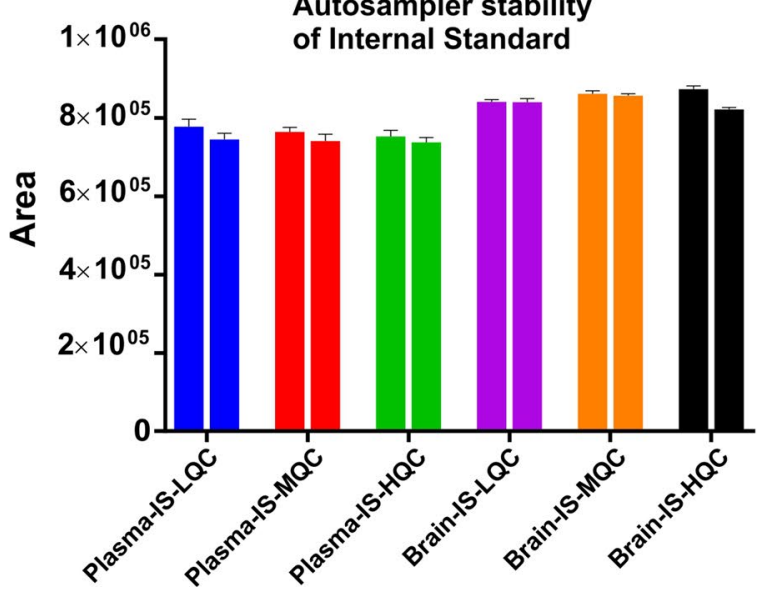

Plasma-IS-LQC

Plasma-IS-MQC

Plasma-IS-HQC

Brain-IS-LQC

Brain-IS-MQC

Brain-IS-HQC

Fig. 4 Benchtop and auto-sampler stability assay. Benchtop stability-Adjacent/grouped/paired columns (two columns with identical color) represent concentrations of control/non-stressed sample (measured immediately after sample preparation, first column) vs concentrations of stability/ stressed sample (samples left at ambient temperature for $10 \mathrm{~h}$ prior to analysis-benchtop delayed, second column). No statistical difference in concentrations (between two adjacent columns) displays benchtop stability at LQC, MQC and HQC concentrations in both plasma and brain (a). Autosampler stability_Adjacent/grouped/paired columns (two columns with identical color) represent absolute peak area of control/non-stressed sample (measured immediately after sample preparation, first column) vs absolute peak area of stability/stressed sample (samples left at autosampler for $12 \mathrm{~h}$ prior to analysis, second column). No statistical difference in absolute peak areas (between two adjacent columns) shows autosampler stability of analytes- nicotine and cotinine (b1) and IS (b2) at LQC, MQC and HQC in both plasma and brain 


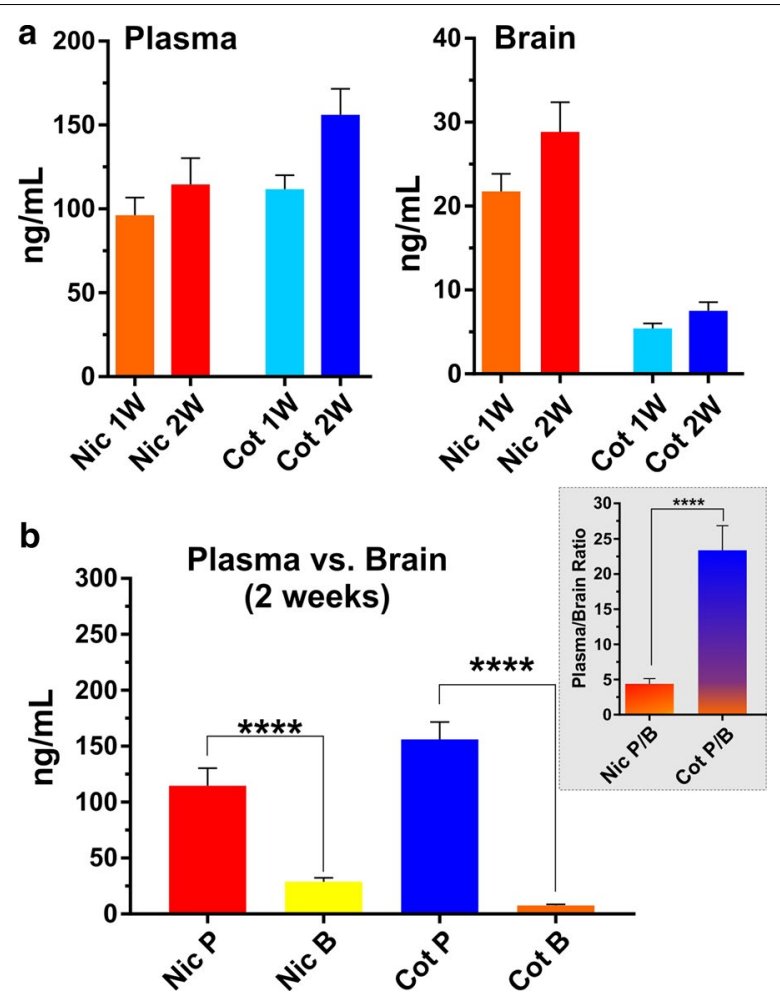

Fig. 5 Plasma and brain levels of nicotine and cotinine in mouse. Nicotine and cotinine concentrations in mouse plasma and brain one and 2 weeks post exposure to TS (a). Plasma versus brain level and plasma : brain ratio of nicotine and cotinine 2 weeks post exposure to TS. ${ }^{* * *} p<0.0001$ plasma concentration of analytes against corresponding brain level, plasma:brain ratio of nicotine against plasma:brain ratio of cotinine $(\mathbf{b}$

the nicotine concentration was found to be $\sim 80 \mathrm{ng} /$ $\mathrm{mL}$ while the cotinine concentration was $\sim 112 \mathrm{ng} / \mathrm{mL}$ in plasma. Two weeks exposure produced a significant elevation of plasma cotinine levels compared to nicotine (> $150 \mathrm{ng} / \mathrm{mL}$ ) as shown in Fig. 5. The concentrations of both nicotine and cotinine were significantly lower in brain than plasma. In brain, cotinine levels was nominal in comparison to nicotine following both one and 2 weeks of exposure. The plasma to brain ratio of nicotine was only five times but for cotinine it was approximately twenty-five times following 2 weeks of exposure.

\section{Discussion}

WHO Report on the Global Tobacco Epidemic, 2013 reveals that tobacco smoking (TS) is accountable for approximately 6 million deaths per year globally with a projection of 8 million deaths annually by 2030. From a neuro-vascular perspective, TS has been associated with vascular endothelial dysfunction [25-27] in a causative and dose dependent manner [28] primarily related to the TS content of reactive oxygen species (ROS) [27,
29], nicotine [30-35], and oxidative stress (OS) - driven inflammation [36]. As such TS is also a major prodromal factor for numerous central nervous system (CNS) disorders including Alzheimer's, depression, cognitive impairment, stroke, and vascular dementia. Despite the strong evidence for an association between smoking and vascular impairment, the impact of TS exposure on the neurovascular unit (NVU) and its underlying pathophysiology has only been marginally addressed, thus leaving this a substantial understudied area.

Several preclinical models for exposing animals to TS were reported to understand the pathophysiology of the diseases caused by TS or TS derived nicotine. However, these models lack in simulating realistic human smoking pattern. Therefore, we report, a newly developed preclinical smoking model using C57BL/6 mice which novelty lies on a more realistic human-like smoking exposure pattern. This typically consists of smoking throughout the awake period with intervals in between cigarettes. Previously, reported exposure regimens do not provide such intervals resulting in continuous exposure ranging from 1 up to $5 \mathrm{~h}$ [37-39].

By contrast, our exposure protocol includes intervals in between exposure to cigarette smoke (puffs) during which animals receive uninterrupted supply of normal oxygenated air. In addition to these inter-puffs intervals, after 2 cigarettes/session are fully consumed, animals are transferred immediately from the smoking chamber back to their regular housings with food and water supply breathing normal oxygenated air before being subjected to the next smoking session. This cycle repeats 6 times per day (7 days a week) with a resting interval of $44 \mathrm{~min}$ in between sessions. The overall smoking exposure level is comparable to that of a heavy chronic smoker. Furthermore, animals undergoing smoking exposure are housed in a smoking chamber where animals are not restrained and/or under anesthesia. The smoking chamber can also house a larger number of animals (16 mice) in contrast to complex designed chambers [40] accommodating relatively less animals. Our exposure regimen is also feasible for both acute and chronic in vivo studies. Also, an additional advantage of our method, is that it can be adapted to routine plasma nicotine and cotinine level monitoring procedure (non-invasive) since analysis requires only $20 \mu \mathrm{L}$ of blood which can easily be collected through the tail vein. Obviously, there are still unavoidable limitation to this model which is due to the fact that through human smoking behavior patterns are dynamic and tend to change during the course of smoking a cigarette. For example, smokers tend to take deeper and longer puffs at the beginning and as the cigarette get consumed these get shorter and smaller in volume. Inter-puff intervals instead, tend to be shortest at the beginning of the 
cigarette and longest near the end. These variable smoking patterns contrast with the static ones that can be currently reproduced by a smoking machine.

However, despite these limitation we believe that our model represents a significant step forward in the field and would be of significant help to researchers working to unmask the effects of TS/nicotine on CNS and its underlying pathophysiology. Findings from these studies can be positively correlated to human's pathophysiology of TS toxicity and to further understand its negative impacts on a more detailed level. Further, in the past decade a number of alternative vaping products have hit the market, rapidly gaining consumers among adults and, especially, adolescents. Electronic nicotine delivery systems or e-cigarettes (e-Cigs) have become the soughtafter product partly due to the belief that they are much safer than traditional cigarettes. Preclinical studies have shown that nicotine (the principal ingredient of e-liquid) can cause OS, exacerbation of cerebral ischemia and secondary brain injury $[11,34,41]$. Likewise, chronic e-Cig vaping could be prodromal to cerebrovascular impairment and promote cerebrovascular conditions similar to that associated with chronic TS. From this point of view, the health impact of e-Cig vaping is currently unknown and the limited research and dearth of regulatory for e-Cigs has become a critical public and regulatory concern. Thus, the development of a reliable in vivo model of chronic TS (and e-Cigs) exposure is even more crucial.

Currently available literature methods lack simpler sample preparation, sensitive method with small plasma volume and short run time. To validate the mouse model, we required a bioanalytical method for the simultaneous estimation of NT and CN both with $3 \mathrm{ng} / \mathrm{mL}$ as LLOQ in plasma and brain homogenate. For the first time we reported a method validation for the quantitative estimation of NT and CN using mouse plasma. The advantage of this method includes small sample volume $(20 \mu \mathrm{L})$, simple protein crashing, sensitive method and short runtime of $3 \mathrm{~min}$. This method can be further extrapolated to various studies involving different strains of mouse.

As mentioned earlier, the plasma level of nicotine of a chronic heavy smoker is up to $100 \mathrm{ng} / \mathrm{mL}$ whereas that of cotinine is $\sim 250$ to $350 \mathrm{ng} / \mathrm{mL}$. Apart from interpersonal/genetic variation in metabolic enzymes responsible for nicotine metabolism and clearance, the plasma concentration of nicotine varies widely depending the interval between sample collection and last time smoked. We collected mouse plasma samples within less than $30 \mathrm{~min}$ following last cigarette smoked. Many reports suggest higher cotinine:nicotine plasma ratio as we observed here in mouse model, fast sample collection explains the fact that, plasma nicotine was not exposed to CYP450 s for enough period of time to be metabolized and cleared off.
There are controversial reports regarding brain uptake of cotinine. Some reports suggest, cotinine is polar in nature compared to nicotine and it does not cross $\mathrm{BBB}$, the presence of cotinine in brain is due to presence of metabolic enzymes in brain that converts nicotine penetrated in brain into cotinine while other reports demonstrated brain uptake of cotinine itself [6]. We here show that, the cotinine concentration in brain is significantly less compared to plasma and brain nicotine level.

\section{Conclusion}

A simple, rapid, sensitive and specific UHPLC-MS/MS method has been developed and validated for quantification of NT and $\mathrm{CN}$ in mouse plasma and brain homogenate as per the regulatory guidelines. The method showed suitability for validating preclinical animal smoking/vaping model using C57BL/6J mice. The simple protein crash method using 8 volumes of acetonitrile furnished consistent and reproducible recoveries for NT, CN and IS from plasma as well as brain homogenate. The simplicity of the extraction process and use of very less sample volume, and sample turnover rate of 3 min per sample, make it an attractive procedure in high-throughput bioanalysis of NT and $\mathrm{CN}$. From the results of all the validation parameters, we can conclude that the developed method can be useful for any further studies in mice where blood volumes are limited per time point. A method with small sample volume from animals involved in research is in line with $3 \mathrm{R}$ principle of replace, reduce and refine animals in research.

\section{Abbreviations \\ CNS: central nervous system; CN: cotinine; e-Cigs: e-cigarettes; GC-MS: gas chromatography-mass spectrometry; HQC: high quality control; IS: internal standard; LC-MS/MS: liquid chromatography-tandem mass spectrometry; LQC: Iow quality control; LLOQ: lower limit of quantification; MQC: middle quality control; MRM: multiple reaction-monitoring; NVU: neuro-vascular unit; NT: nicotine; OS: oxidative stress; QC: quality control; ROS: reactive oxygen species; TS: tobacco smoking.}

\section{Authors' contributions}

KMA and LC conceived the study and drafted the manuscript. KMA also contributed to the experimental execution and data analyses. RRK contributed to the experimental execution and helped with the method validation. RKS and EAS contributed to drafting the manuscript. LC also supervised the project, and provided further guidance during the manuscript preparation and revisions. All authors have read and approved the final version of the manuscript.

\section{Author details}

1 Department of Pharmaceutical Sciences, School of Pharmacy, Texas Tech University Health Sciences Center, 1300 S. Coulter Street, Amarillo, TX 79106, USA. ${ }^{2}$ Office of Sciences, School of Pharmacy, Texas Tech University Health Sciences Center, Amarillo, TX 79106, USA. ${ }^{3}$ Center for Blood Brain Barrier Research, Texas Tech University Health Sciences Center, Amarillo, TX 79106, USA.

\section{Acknowledgements}

Not applicable. 


\section{Competing interests}

The authors declare that they have no competing interests.

\section{Availability of data}

The datasets used and/or analysed during the current study are available from the corresponding author on reasonable request.

\section{Consent to publish}

Not Applicable.

\section{Ethics approval and consent to participate}

All animal procedures were in accordance with the Texas Tech University Health Sciences Center Institutional Animal Care and Use Committee and $\mathrm{NIH}$ federal guidelines.

\section{Funding}

These studies were supported by NIH/NIDA 2R01DA029121-07A1 to Dr. Luca cucullo.

\section{Publisher's Note}

Springer Nature remains neutral with regard to jurisdictional claims in published maps and institutional affiliations.

Received: 6 June 2017 Accepted: 5 October 2017

Published online: 11 October 2017

\section{References}

1. Benowitz NL. Nicotine addiction. N Engl J Med. 2010;362(24):2295-303.

2. National Center for Chronic Disease Prevention and Health Promotion (US) Office on Smoking and Health. The health consequences of smoking-50 years of progress: A report of the surgeon general. Atlanta: Centers for Disease Control and Prevention (US); 2014.

3. Benowitz NL, Hukkanen J, Jacob P 3rd. Nicotine chemistry, metabolism, kinetics and biomarkers. Handb Exp Pharmacol. 2009;192:29-60.

4. Moyer TP, Charlson JR, Enger RJ, Dale LC, Ebbert JO, Schroeder DR, Hurt RD. Simultaneous analysis of nicotine, nicotine metabolites, and tobacco alkaloids in serum or urine by tandem mass spectrometry, with clinically relevant metabolic profiles. Clin Chem. 2002;48(9):1460-71.

5. Hawkins BT, Abbruscato TJ, Egleton RD, Brown RC, Huber JD, Campos CR, Davis TP. Nicotine increases in vivo blood-brain barrier permeability and alters cerebral microvascular tight junction protein distribution. Brain Res. 2004;1027(1-2):48-58.

6. Lockman PR, McAfee G, Geldenhuys WJ, Van der Schyf CJ, Abbruscato TJ, Allen DD. Brain uptake kinetics of nicotine and cotinine after chronic nicotine exposure. J Pharmacol Exp Ther. 2005;314(2):636-42.

7. Lockman PR, Van der Schyf CJ, Abbruscato TJ, Allen DD. Chronic nicotine exposure alters blood-brain barrier permeability and diminishes brain uptake of methyllycaconitine. J Neurochem. 2005;94(1):37-44.

8. Shah KK, Boreddy PR, Abbruscato TJ. Nicotine pre-exposure reduces stroke-induced glucose transporter-1 activity at the blood-brain barrier in mice. Fluids Barriers CNS. 2015:12:10.

9. Lenoir M, Kiyatkin EA. Intravenous nicotine injection induces rapid, experience-dependent sensitization of glutamate release in the ventral tegmental area and nucleus accumbens. J Neurochem. 2013;127(4):541-51.

10. Wakabayashi KT, Kiyatkin EA. Critical role of peripheral drug actions in experience-dependent changes in nucleus accumbens glutamate release induced by intravenous cocaine. J Neurochem. 2014;128(5):672-85.

11. Werley MS, Kirkpatrick DJ, Oldham MJ, Jerome AM, Langston TB, Lilly PD, Smith DC, McKinney WJ Jr. Toxicological assessment of a prototype e-cigaret device and three flavor formulations: a 90-day inhalation study in rats. Inhal Toxicol. 2016:28(1):22-38.

12. Murphy SE, Raulinaitis V, Brown KM. Nicotine $5^{\prime}$-oxidation and methyl oxidation by P450 2A enzymes. Drug Metab Dispos. 2005:33(8):1166-73.

13. Siu EC, Wildenauer DB, Tyndale RF. Nicotine self-administration in mice is associated with rates of nicotine inactivation by CYP2A5. Psychopharmacology. 2006;184(3-4):401-8.
14. Messina ES, Tyndale RF, Sellers EM. A major role for CYP2A6 in nicotine C-oxidation by human liver microsomes. J Pharmacol Exp Ther. 1997:282(3):1608-14

15. Schoedel KA, Sellers EM, Tyndale RF. Induction of CYP2B1/2 and nicotine metabolism by ethanol in rat liver but not rat brain. Biochem Pharmacol. 2001;62(8):1025-36.

16. Nakayama H, Okuda H, Nakashima T, Imaoka S, Funae Y. Nicotine metabolism by rat hepatic cytochrome P450s. Biochem Pharmacol. 1993:45(12):2554-6.

17. Matta SG, Balfour DJ, Benowitz NL, Boyd RT, Buccafusco JJ, Caggiula AR, Craig CR, Collins AC, Damaj MI, Donny EC, et al. Guidelines on nicotine dose selection for in vivo research. Psychopharmacology. 2007;190(3):269-319.

18. Ghosheh O, Dwoskin LP, Li WK, Crooks PA. Residence times and half-lives of nicotine metabolites in rat brain after acute peripheral administration of [2'-(14)C]nicotine. Drug Metab Dispos. 1999:27(12):1448-55.

19. Rowell PP, Li M. Dose-response relationship for nicotine-induced up-regulation of rat brain nicotinic receptors. J Neurochem. 1997:68(5):1982-9.

20. Abdallah IA, Hammell DC, Stinchcomb AL, Hassan HE. A fully validated LC-MS/MS method for simultaneous determination of nicotine and its metabolite cotinine in human serum and its application to a pharmacokinetic study after using nicotine transdermal delivery systems with standard heat application in adult smokers. J Chromatogr B Analyt Technol Biomed Life Sci. 2016;1020:67-77.

21. Tretzel L, Thomas A, Piper T, Hedeland M, Geyer H, Schanzer W, Thevis M. Fully automated determination of nicotine and its major metabolites in whole blood by means of a DBS online-SPE LC-HR-MS/MS approach for sports drug testing. J Pharm Biomed Anal. 2016;123:132-40.

22. Vieira-Brock PL, Miller El, Nielsen SM, Fleckenstein AE, Wilkins DG. Simultaneous quantification of nicotine and metabolites in rat brain by liquid chromatography-tandem mass spectrometry. J Chromatogr B Analyt Technol Biomed Life Sci. 2011;879(30):3465-74.

23. Alsharari SD, Siu EC, Tyndale RF, Damaj MI. Pharmacokinetic and pharmacodynamics studies of nicotine after oral administration in mice: effects of methoxsalen, a CYP2A5/6 inhibitor. Nicotine Tob Res. 2014;16(1):18-25.

24. Scheidweiler KB, Shakleya DM, Huestis MA. Simultaneous quantification of nicotine, cotinine, trans-3'-hydroxycotinine, norcotinine and mecamylamine in human urine by liquid chromatography-tandem mass spectrometry. Clin Chim Acta. 2012;413(11-12):978-84

25. Chen HW, Chien ML, Chaung YH, Lii CK, Wang TS. Extracts from cigarette smoke induce DNA damage and cell adhesion molecule expression through different pathways. Chem Biol Interact. 2004;150(3):233-41.

26. Hossain M, Sathe T, Fazio V, Mazzone P, Weksler B, Janigro D, Rapp E, Cucullo L. Tobacco smoke: a critical etiological factor for vascular impairment at the blood-brain barrier. Brain Res. 2009;1287:192-205.

27. Naik P, Fofaria N, Prasad S, Sajja RK, Weksler B, Couraud PO, Romero IA, Cucullo L. Oxidative and pro-inflammatory impact of regular and denicotinized cigarettes on blood brain barrier endothelial cells: Is smoking reduced or nicotine-free products really safe? BMC Neurosci. 2014;15:51.

28. Gill JS, Shipley MJ, Tsementzis SA, Hornby R, Gill SK, Hitchcock ER, Beevers DG. Cigarette smoking. A risk factor for hemorrhagic and nonhemorrhagic stroke. Arch Intern Med. 1989;149(9):2053-7.

29. Panda K, Chattopadhyay R, Ghosh MK, Chattopadhyay DJ, Chatterjee IB. Vitamin C prevents cigarette smoke induced oxidative damage of proteins and increased proteolysis. Free Radic Biol Med. 1999:27(9-10):1064-79.

30. Catanzaro DF, Zhou Y, Chen R, Yu F, Catanzaro SE, De Lorenzo MS, Subbaramaiah K, Zhou XK, Pratico D, Dannenberg AJ, et al. Potentially reduced exposure cigarettes accelerate atherosclerosis: evidence for the role of nicotine. Cardiovasc Toxicol. 2007;7(3):192-201.

31. Das S, Gautam N, Dey SK, Maiti T, Roy S. Oxidative stress in the brain of nicotine-induced toxicity: protective role of Andrographis paniculata Nees and vitamin E. Appl Physiol Nutr Metab. 2009:34(2):124-35.

32. Hanna ST. Nicotine effect on cardiovascular system and ion channels. J Cardiovasc Pharmacol. 2006:47(3):348-58

33. Heeschen C, Weis M, Cooke JP. Nicotine promotes arteriogenesis. J Am Coll Cardiol. 2003:41(3):489-96.

34. Paulson JR, Yang T, Selvaraj PK, Mdzinarishvili A, Van der Schyf CJ, Klein J, Bickel U, Abbruscato TJ. Nicotine exacerbates brain edema during in vitro and in vivo focal ischemic conditions. J Pharmacol Exp Ther. 2010;332(2):371-9. 
35. Wang L, Kittaka M, Sun N, Schreiber SS, Zlokovic BV. Chronic nicotine treatment enhances focal ischemic brain injury and depletes free pool of brain microvascular tissue plasminogen activator in rats. J Cereb Blood Flow Metab. 1997;17(2):136-46.

36. Arnson $Y$, Shoenfeld $Y$, Amital $H$. Effects of tobacco smoke on immunity, inflammation and autoimmunity. J Autoimmun. 2010;34(3):J258-65.

37. Hwang JW, Sundar IK, Yao H, Sellix MT, Rahman I. Circadian clock func tion is disrupted by environmental tobacco/cigarette smoke, leading to lung inflammation and injury via a SIRT1-BMAL1 pathway. FASEB J. 2014;28(1):176-94.

38. Yao H, Chung S, Hwang JW, Rajendrasozhan S, Sundar IK, Dean DA, McBurney MW, Guarente L, Gu W, Ronty M, et al. SIRT1 protects against emphysema via FOXO3-mediated reduction of premature senescence in mice. J Clin Invest. 2012;122(6):2032-45.
39. Lerner CA, Sundar IK, Yao H, Gerloff J, Ossip DJ, Mclntosh S, Robinson R, Rahman I. Vapors produced by electronic cigarettes and e-juices with flavorings induce toxicity, oxidative stress, and inflammatory response in lung epithelial cells and in mouse lung. PLOS ONE. 2015;10(2):e0116732.

40. Moreno-Gonzalez I, Estrada LD, Sanchez-Mejias E, Soto C. Smoking exacerbates amyloid pathology in a mouse model of Alzheimer's disease. Nat Commun. 2013:4:1495

41. Li C, Sun H, Arrick DM, Mayhan WG. Chronic nicotine exposure exacerbates transient focal cerebral ischemia-induced brain injury. J Appl Physiol. 2016;120(3):328-33.

\section{Submit your next manuscript to BioMed Central and we will help you at every step:}

- We accept pre-submission inquiries

- Our selector tool helps you to find the most relevant journal

- We provide round the clock customer support

- Convenient online submission

- Thorough peer review

- Inclusion in PubMed and all major indexing services

- Maximum visibility for your research

Submit your manuscript at www.biomedcentral com/submit 